\title{
Controlling invasive species by empowering environmental stakeholders: ecotourism boat operators as potential guardians of wildlife against the invasive American mink
}

\author{
Elaine J. Fraser, David W. Macdonald, Rosalind Bryce and Xavier Lambin
}

\begin{abstract}
People who have a stake in their environment are more likely to volunteer to assist conservation but they must be empowered to do so. This study explored the possibility of harnessing volunteers in the control of an invasive predator, the American mink Neovison vison, which decimates seabird colonies in coastal west Scotland. A questionnaire was sent to ecotourism boat operators, a group assumed to have an economic interest in wildlife biodiversity and a stake in their environment, to gauge their opinion on lethal control of American mink. The majority (64\%) of respondents were concerned about the presence of mink in their area, agreed with control in principle and were willing to become involved in a volunteer capacity. Respondents who would not volunteer but agreed with control (21\%) might reconsider if mink had a visible impact on their local wildlife. The minimum level of support people expected was information on where to get, and how to deploy, monitoring and trapping equipment. This study confirms that people with an intrinsic interest in wildlife consider themselves willing to protect their local biodiversity, with only limited resource input, such as an information pack, from external sources.
\end{abstract}

Keywords American mink, control, environmental stakeholders, invasive species, native species conservation, Neovison vison, Scotland, volunteer involvement

\section{Introduction}

Tnvasive species are those introduced by human agency 1 and which subsequently spread and cause damage to the ecosystems in which they have been introduced. Biological invasions are a major global threat to biodiversity and ecosystem function (Kolar \& Lodge, 2001). Invasive

ELAINE J. Fraser*, Rosalind BRYCE and XAVIER LAMBIN (Corresponding author) School of Biological Sciences, University of Aberdeen, Aberdeen, AB24 2TZ, UK. E-mail x.lambin@abdn.ac.uk

David W. Macdonald Wildlife Conservation Research Unit, Department of Zoology, University of Oxford, UK

* Also at: Wildlife Conservation Research Unit, Department of Zoology, University of Oxford, UK

Received 17 July 2012. Revision requested 7 January 2013.

Accepted 4 March 2013. First published online 19 February 2014. predatory species can have a devastating impact on native species (Simberloff, 2001) and biodiversity conservation (Macdonald et al., 2007) and there is an increasing awareness of, and necessity for, management to minimize these impacts (Bryce et al., 2011).

Control of invasive species on a large scale has been attempted using various methods. For example, successful eradication of the coypu Myocastor coypus in Britain was accomplished using salaried trappers who were given bonuses for early completion (Gosling \& Baker, 1989). Eradications of introduced rats and cats on islands, using poison baiting, have proven successful (Howald et al., 2010; Ratcliffe et al., 2010) but the use of poison for controlling carnivores in populated areas of Europe is unlikely to be acceptable to the public (Genovesi, 2005). Nevertheless, public support can be gained for control efforts, particularly when humans are viewed as responsible for the invasion (Selge et al., 2011). Attempts to control the American mink Neovison vison in Europe have been conducted using dedicated salaried trappers, paying a bounty to hunters, and through the use of volunteers who have an interest in removing mink (Bonesi \& Palazon, 2007; Bryce et al., 2011; Scottish Natural Heritage, 2012).

Involving unpaid volunteers in collating information on the distribution (e.g. Delaney et al., 2008; Dickinson et al., 2010; Gallo \& Waitt, 2011) and control of invasive species on a large scale is a feasible alternative to the costly use of professional staff (Tidwell \& Brunson, 2008; Bryce et al., 2011; Macdonald \& Burnham, 2011). People willing to participate in invasive species management often have a stake in the environment (Tidwell \& Brunson, 2008; Selge et al., 2011), making it possible to connect with the motivations of such stakeholders to promote voluntary participation in the management of invasive species.

Success with volunteer-based invasive species control was demonstrated by Bryce et al. (2011) for their mink control project. This project aimed to eradicate breeding mink from an area of north-east Scotland, to allow recovery of native species such as the water vole Arvicola amphibius. It involved a wide range of volunteers who had convergent economic and general interests in protecting vulnerable native species. The project has now expanded from its original coverage (Area 1, Fig. 1) and aims to replicate this success across a larger area of mainland Scotland (Area 2, Fig. 1). 


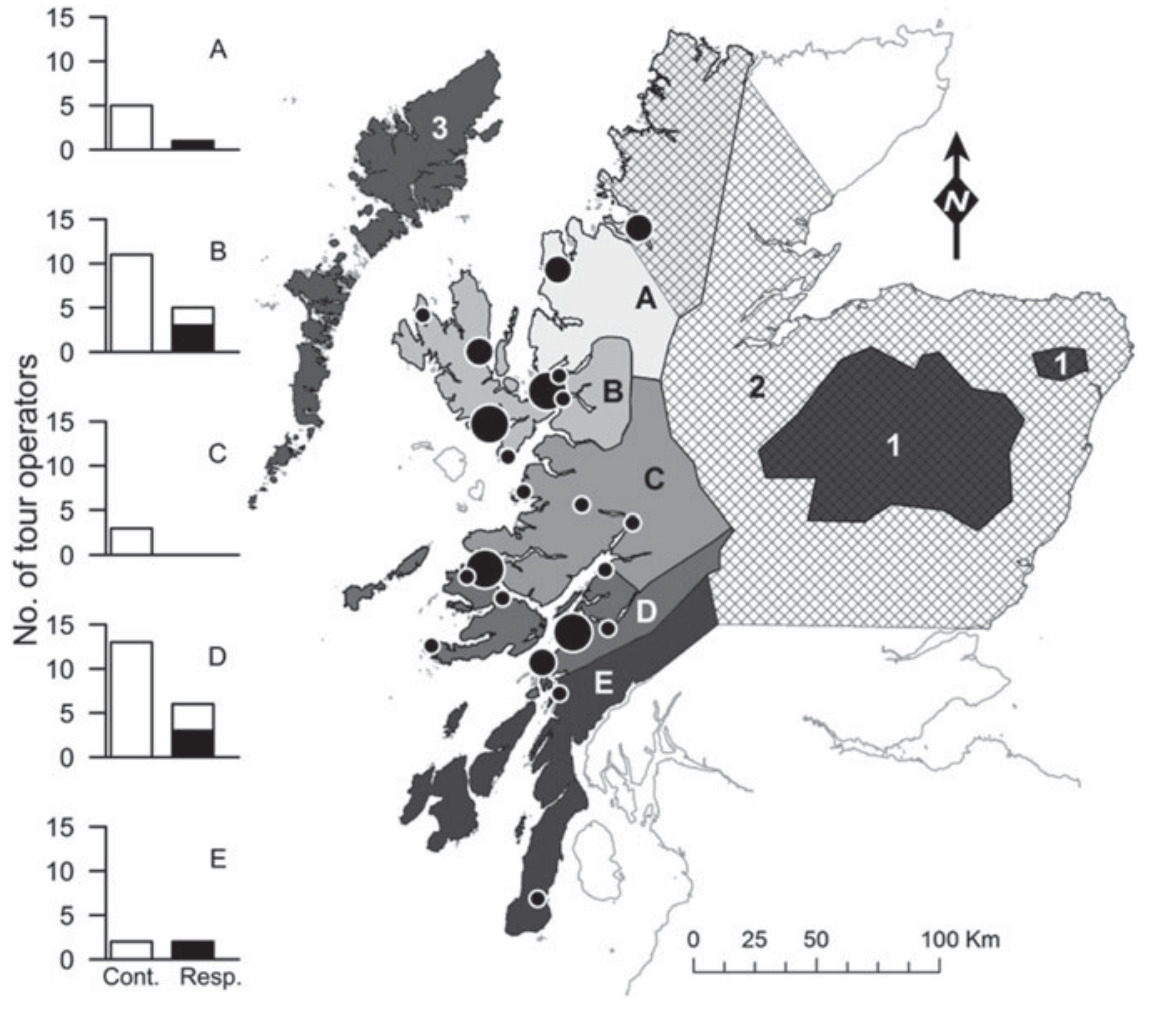

FIG. 1 Scotland, showing geographical locations mentioned in the text. Areas A-E show regional boundaries used to describe locations of west coast tour operators (A, North Highland; B, Skye and Lochalsh; C, Fort William and Lochaber; D, Oban and Mull; E, Mid Argyll and Kintyre). The gradation of shading from south to north (areas E to A) represents the pattern of colonization by mink on the west coast. Other mink project areas are represented by numbers (1, original mink project area; 2 , current mink project area; 3, Outer Hebrides project area). The locations of all businesses contacted for the questionnaire are indicated by black dots, where the size represents number of businesses at each location ( small $=1$, medium $=2$, large $=3$ ). Bar graphs show the number of tour boat operators who were contacted (Cont.) and responded (Resp.) and of those respondents, the number who were willing to volunteer (black section of bar), in each area (letters correspond as above).
The invasive American mink was introduced to many locations outside its native range, including the UK, for fur farming (Cuthbert, 1973). Feral populations have established from escaped and released mink. Mink are opportunistic predators that feed on a range of native species including small mammals, fish, frogs, crustaceans, and birds and their eggs (Dunstone, 1993; Macdonald \& Harrington, 2003). They are highly dispersive and inhabit coastal and inland freshwater habitats, the former of which is assumed to be more productive and hence to accommodate denser mink populations (Dunstone, 1993; Clode et al., 1995; Bodey et al., 2010).

The detrimental impact of mink on native birds in the invaded range worldwide is well documented (e.g. Craik, 1997; Nordström et al., 2003; Peris et al., 2009) and can involve direct killing, desertion of colonies, or breeding failures as a result of disturbance during incubation (Burness \& Morris, 1993; Clode \& Macdonald, 2002). Coastal areas are worst affected, exemplified by studies showing poor breeding success and loss or relocation of many seabird colonies (Clode \& Macdonald, 2002; Nordström \& Korpimäki, 2004; Ratcliffe et al., 2008). However, mink control has proven successful in reversing this damage, resulting in increases in diversity and breeding densities of seabirds (Nordström et al., 2003; Ratcliffe et al., 2008) and re-establishment of colonies previously decimated by mink predation (Ratcliffe et al., 2008).

In Scotland mink are present in all but far northern areas (DAISIE, 2012; NBN Gateway, 2012). The north-west coast has been the most recently invaded, leading to growing concern about the impact of mink on wildlife, as well as the potential for further detriment if the far north of the country is colonized.

The volunteers involved in mink control in east Scotland were initially sourced from areas dependent on revenue from grouse shooting and recreational salmon fishing (Bryce et al., 2011). The rural economy in west Scotland is not comparable but instead is increasingly focused on tourism, including wildlife-watching (Blake et al., 2010; Bryden et al., 2010), often associated with land and water-based tours. Ecotourism operators are expected to have a good perception of the distribution and abundance of mink (and other wildlife) because of the regularity in which they tour extensive areas. They are also assumed to have an interest (business and/or personal) in conserving local wildlife. This stake in their environment may influence their willingness to participate in invasive species management. However, for the most part, they are seemingly not involved in activities contributing to this assumed interest and are not yet within the reach of the large-scale mink project (Area 2, Fig. 1).

There have been several attempts to control mink in mainland western Scotland, with the aim of protecting seabirds (Craik, 1997; Wilson, 2008) but these have been short term, localized in area, and difficult to sustain in the absence of secure long-term financial and labour support. A full-scale eradication of mink from the Outer Hebrides of Scotland (Area 3, Fig. 1) is currently in progress, 
also with the main aim of protecting seabirds (Scottish Natural Heritage, 2012). Although likely to be successful, this project is not replicable on the mainland because of the high financial and labour costs, as well as the low probability of complete eradication. Is a volunteer approach a feasible alternative? Is it possible to harness assumed interest by ecotourism operators in low cost, localized coastal mink control in areas beyond the boundary of the ongoing large-scale volunteer-based project? This could be either as a precursor, or as a new approach, integrating with the current large-scale project as it expands. This study sought to assess the perceived impact of mink on coastal wildlife, and opinions on the ensuing effect on businesses, and to determine the level of support required to mobilize this potential source of volunteers. However, we did not seek to quantify or place a value on the impact of mink on wildlife or ecotourism businesses.

The aim was to provide clear guidance on the external input required to mobilize volunteers who could work towards achieving local protection of key bird colonies in their coastal communities. In addition, it was important to ascertain whether inaction to date by professionals who have a stake in local biodiversity and the invasive-native conflict actually reflects insufficient interest or a lack of empowerment.

\section{Methods}

The perception of ecotourism boat operators towards mink was assessed by a questionnaire, structured using both closed-format and open-ended questions. The survey was issued to all ecotourism boat operators from western Scotland who fitted the selection criteria (in July 2011) of advertising boat trips for wildlife watching (not necessarily exclusively), having a business based on the west coast and providing a contact e-mail address. This gave a total of 34 potential respondents in five regional areas: Northern Highlands, Skye and Lochalsh, Fort William and Lochaber, Oban and Mull, and Mid Argyll and Kintyre (Fig. 1).

The questionnaire was designed and run as a web-based survey, using SNAP 10 Professional (Snap Surveys, London, UK), in accordance with the ethical guidelines of the University of Aberdeen. Participants were given 4 weeks to complete the survey and were sent two reminders during this time if they had not responded. A paper version of the questionnaire was also available on request. Responses were anonymous unless participants chose to include an e-mail address in their response.

Respondents were first asked to give opinions about their business priorities, followed by questions directed towards considering the benefits of mink control, their willingness to participate, and at what cost they would involve themselves. The questions were interspersed with informative text about mink and mink control, including

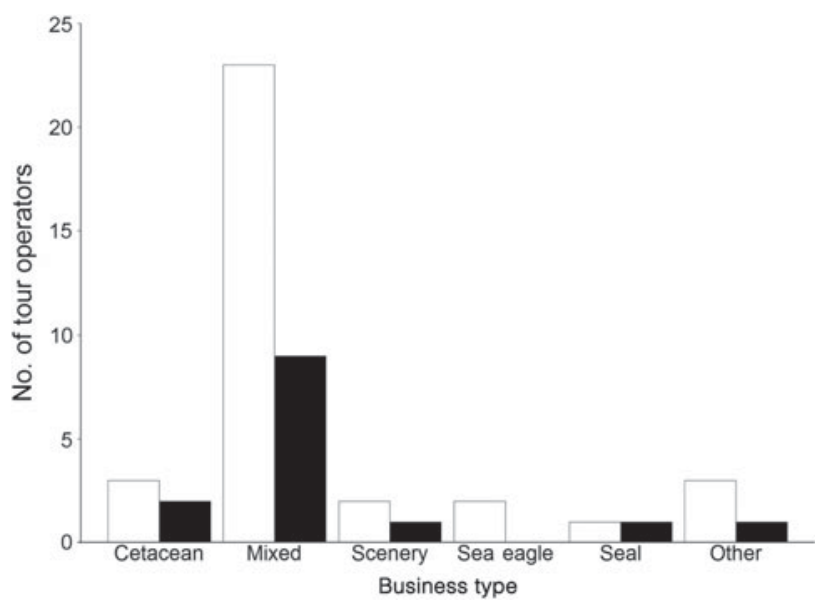

FIG. 2 Number of ecotourism boat operators contacted (white bars) and number who responded (black bars), according to primary business type (cetacean watching, mixed wildlife watching, scenic tours, sea eagle watching, seal watching and other activities).

the cost of equipment and an outline of the time commitment required when volunteering. Following the first section of informative text, respondents were asked to re-answer several questions taking into account the information provided. This was done so that all respondents were answering with at least the same level of knowledge.

\section{Results}

Fourteen complete questionnaires were returned, an above average response rate of $41 \%$ (cf. Cook et al., 2000; Dillman et al., 2009). The highest numbers of respondents were from Skye and Lochalsh, and Oban and Mull (Fig. 1). This reflected the number of businesses located in these areas (Fig. 1). A variety of business types responded; the most common was mixed wildlife watching (Fig. 2). Most businesses were $>6$ years old, with five operating for $>20$ years. All but one respondent reported either seeing mink or being aware of the presence of mink in their area. These are all areas where mink have been recorded (Fig. 1). All but two respondents stated that they agreed with the principle of mink control.

The most common opinion expressed by respondents in relation to mink affecting business and local wildlife was the loss of ground-nesting birds from offshore islands and/or their failure to breed. Terns Sterna spp. were mentioned specifically. Example comments were 'terns no longer present', 'all ground-nesting birds on a local nest site produced zero chicks this year', 'adult birds remain but no chicks', and 'the declining number of species over the last few years has reduced customer enjoyment, and has been commented upon by them'. This concern was in line with their reports of the most common animals they expect to see on their trips (all 14 tour operators expect to see seals and seabirds). 

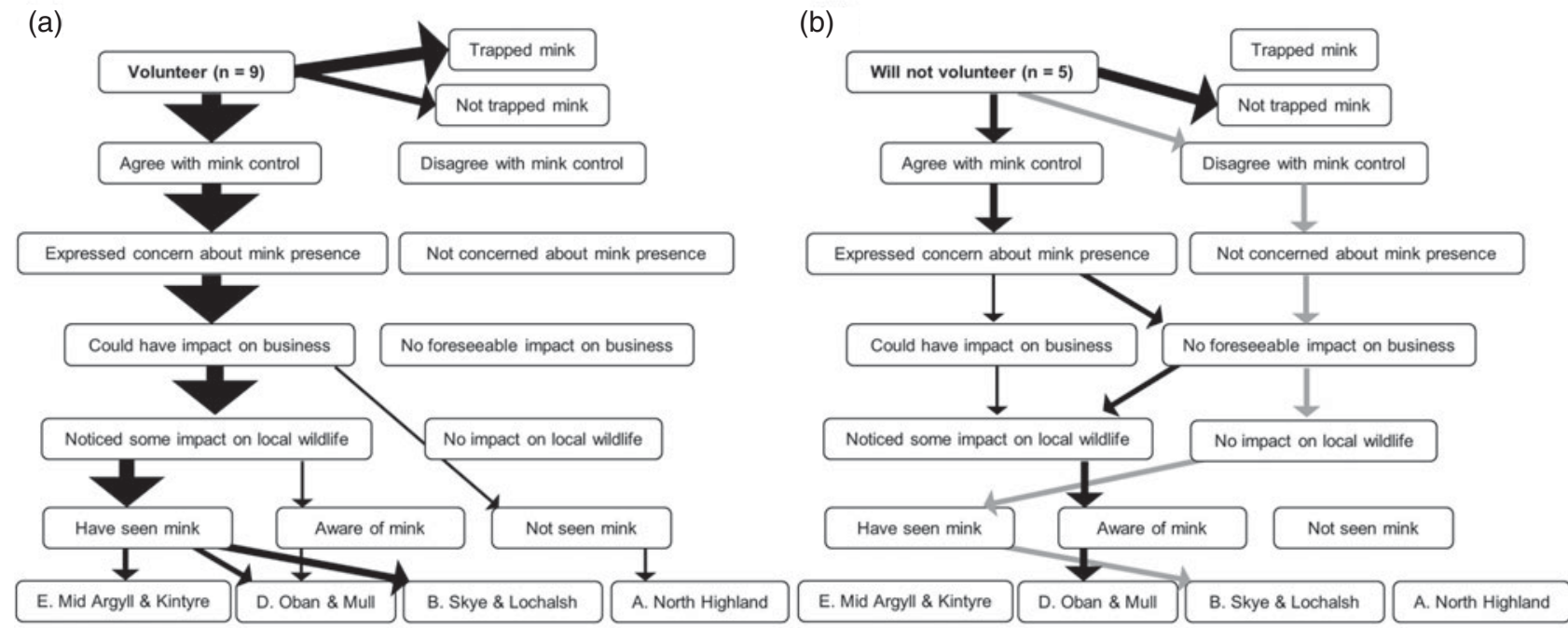

FIG. 3 Characteristics of respondents who were willing to volunteer (a) and those who were not (b), based on their responses to the questionnaire. The thickness of the arrow represents the number of respondents who answered the question with a particular response. In (b) the black arrows show the opinions of respondents who agreed with mink control and the grey arrows show the opinions of those who didn't agree with mink control.

In response to the informative text provided throughout the questionnaire about mink and their control, respondents changed few of their original answers. Assuming that all respondents read the informative text, this suggests they were already well informed. After reading the informative text two respondents raised their level of concern about the presence of mink in their area and two other respondents increased the level of impact they thought mink could have on their business. One person decreased the impact level.

When asked who should be responsible for mink control, the general consensus was that it should be shared amongst the suggested groups. These were government organizations, national conservation NGOs, local conservation NGOs and local individuals with a personal interest, with an additional option for other suggestions. Opinions did not change after reading about the various organizations and projects that already operate.

Nine respondents would consider becoming involved in mink control. They were all concerned about the presence of mink, thought that mink had a visible or highly visible impact on their local wildlife and reported an impact, or potential impact, on their business. Six of these respondents had trapped mink before (Fig. 3).

Of the five respondents who would not volunteer, three agreed and two disagreed with mink control. Those who agreed with control were concerned about the presence of mink and had noticed a low level of impact on local wildlife. They were less concerned about the possible impact of mink on their business. However, two suggested they would volunteer if they noticed an impact on their local wildlife (presumably an increased impact) and the third suggested they would do so if they had time. The two respondents who disagreed with mink control shared the opinion that they were not concerned about the presence of mink and saw no impact, or potential impact, on their local wildlife or business, despite seeing mink in their area (Fig. 3). These respondents did not believe that any factor would change their minds about volunteering for mink control.

People who had seen mink were more likely to volunteer to become involved in mink control than those who were only aware of their presence. Seven people who had seen mink would volunteer, two would not, whereas among those only aware of the presence of mink, one person would volunteer whereas three would not (Fig. 3).

The circumstances in which respondents stated they would consider undertaking mink control were evenly mixed between noticing an impact on their business $(\mathrm{n}=3)$, expansion of the current large-scale project $(\mathrm{n}=3)$, and when someone else organizes it $(\mathrm{n}=3)$. The commonest answer $(n=4)$ was when enough support and/or information was provided (Table 1 ).

When asked what minimum level of support participants would expect if they were to volunteer, the most popular options were information on where to buy, and how to set up, monitoring equipment (e.g. rafts and tunnels; see Reynolds et al., 2004 for information; Table 1). A few respondents would also like training on how to set up monitoring equipment and how to dispatch mink humanely ( $\mathrm{n}=3$ and $\mathrm{n}=2$, respectively). None of the potential volunteers requested provision of a local 
TABLE 1 Range of answers to the questions A. 'At what point do you think you would consider getting involved in mink control? (tick more than one if necessary)' and B. 'If you were willing to do this, what minimum level of support would you expect? (tick as many as you think are necessary)'. The white section shows answers from respondents who were willing to volunteer and the grey sections show answers from those who would not volunteer. The dark grey highlights respondents who disagree with mink control. All other respondents agree with control.

\begin{tabular}{|c|c|c|c|c|c|c|c|c|c|c|c|c|c|c|}
\hline & \multicolumn{9}{|c|}{ Volunteers } & \multicolumn{5}{|c|}{ Non-volunteers } \\
\hline & 1 & 2 & 3 & 4 & 5 & 6 & 7 & 8 & 9 & 10 & 11 & 12 & 13 & 14 \\
\hline \multicolumn{15}{|l|}{ A. When would you get involved in mink control? } \\
\hline $\begin{array}{l}\text { When you are significantly concerned about the } \\
\text { wildlife in your area }\end{array}$ & & $\checkmark$ & & & & & $\checkmark$ & & $\checkmark$ & $\checkmark$ & $\checkmark$ & & & $\checkmark$ \\
\hline When you notice an impact on your business & & & & & & & & $\checkmark$ & & $\checkmark$ & & & & \\
\hline When the Scottish Mink Initiative* reaches your area & & & & $\checkmark$ & $\checkmark$ & & & $\checkmark$ & & & & & & \\
\hline $\begin{array}{l}\text { When someone else organizes it before the Scottish } \\
\text { Mink Initiative* reaches your area }\end{array}$ & $\checkmark$ & & & & & & $\checkmark$ & $\checkmark$ & & & & & & \\
\hline $\begin{array}{l}\text { When enough support/information is provided to } \\
\text { help you carry out control yourself }\end{array}$ & & & $\checkmark$ & & $\checkmark$ & $\checkmark$ & $\checkmark$ & & & & & & & \\
\hline Other & & & $\checkmark^{1}$ & $\sqrt{ }^{2}$ & & & & & & & & $\sqrt{ }^{3}$ & & \\
\hline Still not interested & & & & & & & & & & & & & $\checkmark$ & $\checkmark$ \\
\hline \multicolumn{15}{|l|}{$\begin{array}{l}\text { B. What minimum level of support would you } \\
\text { expect? }\end{array}$} \\
\hline Information on where to buy the equipment & $\checkmark$ & $\checkmark$ & $\checkmark$ & $\checkmark$ & & $\checkmark$ & & $\checkmark$ & & & & & & \\
\hline $\begin{array}{l}\text { Instructions on how to build your own rafts and } \\
\text { tunnels }\end{array}$ & $\checkmark$ & & & & $\checkmark$ & & & $\checkmark$ & & & & & & \\
\hline $\begin{array}{l}\text { Written details on how and where to set rafts, tunnels } \\
\text { and traps }\end{array}$ & $\checkmark$ & $\checkmark$ & & $\checkmark$ & $\checkmark$ & $\checkmark$ & & $\checkmark$ & & & & & & \\
\hline Written advice on how to dispatch effectively & & & $\checkmark$ & $\checkmark$ & & & & & & & $\checkmark$ & & & \\
\hline $\begin{array}{l}\text { Training on how and where to set rafts, tunnels and } \\
\text { traps }\end{array}$ & $\checkmark$ & & & $\checkmark$ & $\checkmark$ & & & & & & $\checkmark$ & & & \\
\hline Training on how to dispatch effectively & & & $\checkmark$ & $\checkmark$ & & & & & & & & & & \\
\hline A local person to contact to dispatch trapped mink & & & & & & & & & & $\checkmark$ & $\checkmark$ & & & \\
\hline Other & & & & & & & $\checkmark^{4}$ & & & & & & & \\
\hline None of the above & & & & & & & & & & & & $\checkmark$ & $\checkmark$ & $\checkmark$ \\
\hline
\end{tabular}

${ }^{*}$ Scottish Mink Initiative is the name of the current volunteer-based mink control project in Scotland (covering Area 2 in Fig. 1).

Reasons for choosing 'Other': ${ }^{1}$ Cost of traps is prohibitive; ${ }^{2}$ Would be involved if there was evidence mink were present; ${ }^{3}$ When time allows; ${ }^{4} \mathrm{Will}$ provide boat transport but needs someone to trap onshore, and also wants expenses.

dispatcher, i.e. someone trained to dispatch trapped mink humanely (Table 1). In the absence of financial resources the possibility of being provided with mink trapping equipment was not offered at this stage of the questionnaire although the cost of equipment was detailed. Therefore it was assumed that respondents understood they would be responsible for financing their involvement. Respondents who chose not to select any options could not be encouraged to change their mind when later given the opportunity of having equipment provided for them.

When asked hypothetically what level of control the respondents would be willing to carry out, most of those that were interested said they would be likely to continue year round, as opposed to once or twice per year. No ecotourism boat operator was willing to incorporate mink control in their regular tours.

\section{Discussion}

This survey of ecotourism boat operators in west Scotland suggests that people who are willing to participate in mink control would do so at their own cost and initiative if they are given written guidance on how to carry it out. The collated questionnaire answers suggest that the guidance required is likely to be of low resource input and at a minimum could be a brochure or information pack detailing where to source monitoring equipment and traps, how to deploy equipment and how to humanely and lawfully dispatch mink once caught. This information should be specific to the locale of the intended mink control but would follow established guidelines. The Game and Wildlife Conservation Trust have conducted extensive research regarding the most efficient and humane ways to monitor, trap and dispatch mink, and this information 
is both publicly available (Game \& Wildlife Conservation Trust, 2012) and internationally recognized as being of high welfare standards (Universities Federation for Animal Welfare, 2012). Several mink control projects have received extensive media coverage (e.g. BBC, 2011a,b) and have been well received by the public and thus any project resulting from this study should be neither misinformed nor misconstrued.

The level of response to the questionnaire reflects a high motivation amongst the target group but it must be remembered that respondents are self-sampled. This small study infers that people with a stake in their environment can be encouraged to act to control invasive species. It also suggests that current inaction may be attributed to lack of empowering information, rather than lack of interest.

Respondents were given details on the cost of equipment and were initially not offered any financial support, thereby implying they would be responsible for financing their own involvement in mink control. Only one respondent asked for expenses to be paid and those who were offered equipment, after stating they would not volunteer, would not accept this as encouragement to be involved. The extent to which the economy of the tourism industry in Scotland is affected by the presence of invasive species is unknown. However, the annual cost of invasive species to the British economy in general has been estimated to be GBP1.7 billion (Williams et al., 2010). It is therefore difficult to predict whether the investment by tour operators in mink control would be recouped through increased business, or through preventing loss of business. However, respondents appeared to be more concerned about their local wildlife than the direct impact on their business (Table 1). Several respondents expressed the opinion that mink had a high level of impact on local wildlife, particularly seabirds. Whether this opinion is based on fact (e.g. Craik, 1997) or perception, it is clearly a motivation for volunteering in mink control.

The potential for 9 of 34 businesses to implement mink control may appear too few, especially considering several respondents were from the same area, but localized impacts are achievable and can contribute to wider-scale successes. Invasive species management relies on action at a local scale but can be more successful when coordinated as part of a larger scale strategic approach (Grice et al., 2011). By coordinating control efforts, volunteers could increase the effectiveness of their activities as well as reduce the risk of reinvasion (Epanchin-Niell et al., 2010). Such an approach has improved the success of fox Vulpes vulpes control on farms in Australia (McLeod et al., 2010) as well as mink control in Scotland (Bryce et al., 2011). In the study by Bryce et al. (2011) the initial core group of volunteers (gamekeepers) were conducting mink control at a local level before the project began. Approximately 60-70 mink were trapped annually within the project area prior to the project commencing but control became regionally effective once the volunteers were coordinated at a landscape level (Bryce et al., 2011). The number of trapped mink within the same area in 2008 was c. 70 but in 2011 was $<20$ (Y. Melero, pers. comm.).

Harrington et al. (2009) proposed that mink control at a local level can be effective but continual monitoring and reactive trapping is necessary, as immigration can rapidly nullify small-scale control efforts. The optimal area for effective mink control is unknown (Harrington et al., 2009) but, intuitively, the larger the better. It has been suggested that at least 3 months of trapping per year is necessary to maintain densities of mink low enough to protect water voles, and that trapping is most effective during the mink mating season in spring (Bonesi et al., 2007; Harrington et al., 2009). Assuming the same low densities of mink would be sufficient to protect seabirds, a high trapping effort in early spring would benefit seabirds by removing mink prior to birds settling at breeding sites. Most tour operators stated they would be willing to conduct control throughout the year and so should be able to volunteer during this preferred trapping season. Anything more than local control of mink on an annual basis would be dependent on the proportion of coastline encompassed and the commitment of volunteers. Predator removal for protection of birds can be successful on islands (Smith et al., 2010), whereas mainland control is less likely to have long-term effects if effort is not maintained. Projects that are expected to sustain action for prolonged periods of time are most effective when participatory and self-mobilized (Evely, 2010), an approach that this study and others (e.g. Bryce et al., 2011) would encourage. This small study suggests that the level of community involvement that could be developed on the west coast of Scotland has the potential to control mink to a level that could provide local protection to seabird colonies. Many bird populations are able to withstand egg predation by native predators (Coté \& Sutherland, 1997) and so it may not be necessary to strive for complete eradication of the invasive species for breeding bird populations to be maintained.

Because of the uneven distribution of ecotourism boat operators on the west coast of Scotland the effort allocated to mink control could be equally patchy. However, the principles and methods applied in this study should be adaptable to other sectors of the community who may be directly and indirectly affected by mink presence, e.g. fish farm operators, sea kayak outfitters or amateurs, and landbased tour companies, and hence a wider coverage could be achieved. In reality it may be difficult to initiate a selffunded, self-propelled project such as this and therefore we recommend that there is some level of coordination; e.g. by local wildlife groups, community champions or other volunteers. The coordinator could also play a vital role in relaying information between volunteers and researchers monitoring the success of the control efforts. There is often 
a time lag between implementation of a project and delivery of results but interim results may aid volunteer motivation. By demonstrating success in other comparable projects and emphasizing local and regional benefits, such as the $73 \%$ increase in black guillemot Cephus grylle numbers following mink control on an island visited by tour operators (Sanda island, Argyll, 1997-1999; Jardine, 2007), it is likely that the number of volunteers would spread outward from a core group.

The opportunities to apply these methods to other invasive species management projects are plentiful. Projects involving fox control in Australia have shown that community-based programmes can be effective when coordinated at a landscape scale (McLeod et al., 2010) and can be self-propelled, particularly when control methods are acceptable to all potential participants (McLeod et al., 2011). A sense of ownership of a project can lead to increased support by participants (McLeod et al., 2011) and by targeting people with a stake in their environment, particularly an economic one, volunteer-based invasive species management can be an effective way to tackle a growing problem. The local impact of volunteer-led efforts over time could entice other communities to undertake similar initiatives and to take an active role in preserving their local biodiversity resources.

\section{Acknowledgements}

We thank all tour operator respondents for taking the time to complete the questionnaire. We also thank Mark Reed and John Lemon for their help and advice in designing the questionnaire and running SNAP. EJF is funded by a Scottish Natural Heritage studentship, as well as receiving funding from the University of Aberdeen and University of Oxford. XL was supported in part by a Leverhulme Trust Research Fellowship.

\section{References}

B BC (2011a) American Mink 'Safe Haven' Project Underway. Http:// www.bbc.co.uk/news/uk-scotland-13360874 [accessed 16 May 2012]. B BC (2011b) American Mink Trapping On Western Isles Extended. Http://www.bbc.co.uk/news/uk-scotland-highlands-islands15006725 [accessed 17 May 2012].

Blake, A., Curtin, S., Brackstone, J., Richards, S., Vaughan, R., Edwards, J. \& Fletcher, J. (2010) The Economic Impact of Wildlife Tourism in Scotland. Http://www.scotland.gov.uk/ Resource/Doc/311941/0098485.pdf [accessed 15 May 2012].

Bodey, T.W., Bearhop, S., Roy, S.S., Newton, J. \& McDonald, R.A. (2010) Behavioural responses of invasive American mink Neovison vison to an eradication campaign, revealed by stable isotope analysis. Journal of Applied Ecology, 47, 114-120.

Bonesi, L. \& Palazon, S. (2007) The American mink in Europe: status, impacts, and control. Biological Conservation, 134, 470-483.
Bonesi, L., Rushton, S.P. \& Macdonald, D.W. (2007) Trapping for mink control and water vole survival: identifying key criteria using a spatially explicit individual based model. Biological Conservation, 136, 636-650.

Bryce, R., Oliver, M.K., Davies, L., Gray, H., Urquhart, J. \& LAMBIN, X. (2011) Turning back the tide of American mink invasion at an unprecedented scale through community participation and adaptive management. Biological Conservation, 144, 575-583.

Bryden, D.M., Westbrook, S.R., Burns, B., Taylor, W.A. \& Anderson, S. (2010) Assessing the Economic Impacts of Nature Based Tourism in Scotland. Scottish Natural Heritage Commissioned Report no. 398.

Burness, G.P. \& MorRIs, R.D. (1993) Direct and indirect consequences of mink presence in a common tern colony. Condor, 95, 708-711.

Clode, D., Haliwell, E.C. \& Macdonald, D.W. (1995) A comparison of body condition in riverine and coastal mink (Mustela vison). Journal of Zoology, 237, 686-689.

Clode, D. \& Macdonald, D.W. (2002) Invasive predators and the conservation of island birds: the case of American mink Mustela vison and terns Sterna spp. in the Western Isles, Scotland. Bird Study, 49, 118-123.

Cоок, C., Неath, F. \& Thompson, R.L. (2000) A meta-analysis of response rates in Web- or Internet-based surveys. Educational and Psychological Measurement, 60, 821-836.

Coté, I.M. \& Sutherland, V. (1997) The effectiveness of removing predators to protect bird populations. Conservation Biology, 11, 395-405.

Craik, C. (1997) Long-term effects of North American Mink Mustela vison on seabirds in Western Scotland. Bird Study, 44, 303-309.

Cuthiert, J.H. (1973) The origin and distribution of feral mink in Scotland. Mammal Review, 3, 97-103.

DAisie (Delivering Alien Invasive Species Inventories for Europe) (2012) Mustela vison Species Factsheet. Http://www. europe-aliens.org/speciesFactsheet.do? speciesId $=52880$ \# [accessed 12 May 2012].

Delaney, D.G., Sperling, C.D., Adams, C.S. \& Leung, B. (2008) Marine invasive species: validation of citizen science and implications for national monitoring networks. Biological Invasions, $10,117-128$.

Dickinson, J.L., Zuckerberg, B. \& Bonter, D.N. (2010) Citizen science as an ecological research tool: challenges and benefits. Annual Review of Ecology, Evolution, and Systematics, $41,149-172$.

Dillman, D.A., Phelps, G., Tortora, R., Swift, K., Kohrell, J., Berck, J. \& Messer, B.L. (2009) Response rate and measurement differences in mixed-mode surveys using mail, telephone, interactive voice response (IVR) and the Internet. Social Science Research, 38, 1-18.

Dunstone, N. (1993) The Mink. T \& AD Poyser, London, UK. Epanchin-Niell, R.S., Hufford, M.B., Asian, C.E., Sexton, J.P., PorT, J.D. \& WARING, T.M. (2010) Controlling invasive species in complex social landscapes. Frontiers in Ecology and the Environment, 8, 210-216.

Evely, A. (2010) An investigation into integrating knowledge for conservation. PhD thesis. University of Aberdeen, Aberdeen, UK.

Gallo, T. \& WAitT, D. (2011) Creating a successful citizen science model to detect and report invasive species. Bioscience, 61, 459-465.

Game \& Wildlife Conservation Trust (2012) Game \& Wildlife Conservation Trust Species Research-Mink. Http://www.gwct.org. $\mathrm{uk} / \mathrm{research} /$ species/mammals/american-mink [accessed 17 May 2012].

Genovesi, P. (2005) Eradications of invasive alien species in Europe: a review. Biological Invasions, 7, 127-133. 
Gosling, L.M. \& BAKeR, S.J. (1989) The eradication of muskrats and coypus from Britain. Biological Journal of the Linnean Society, $38,39-51$.

Grice, A.C., Clarkson, J.R. \& Calvert, M. (2011) Geographic differentiation of management objectives for invasive species: a case study of Hymenachne amplexicaulis in Australia. Environmental Science and Policy, 14, 986-997.

Harrington, L.A., Harrington, A.L., Moorhouse, T., Gelling, M., Bonesi, L. \& Macdonald, D.W. (2009) American mink control on inland rivers in southern England: an experimental test of a model strategy. Biological Conservation, $142,839-849$.

Howald, G., Donlan, C.J., Faulkner, K.R., Ortega, S., Gellerman, H., Croll, D.A. \& Tershy, B.R. (2010) Eradication of black rats Rattus rattus from Anacapa Island. Oryx, 44, 30-40.

Jardine, D. (2007) Black guillemot. In Birds of Argyll (eds T. ap Rheinallt, J.C.A. Craik, P. Daw, B. Furness, S. Petty \& D. Wood), p. 246. Argyll Bird Club, Lochgilphead, UK.

Kolar, C.S. \& Lodge, D.M. (2001) Progress in invasion biology: predicting invaders. Trends in Ecology and Evolution, 16, 199-204.

Macdonald, D.W. \& Burnham, D. (2011) The State of Britain's Mammals. PTES, London, UK.

Macdonald, D.W. \& Harrington, L.A. (2003) The American mink: the triumph and tragedy of adaptation out of context. New Zealand Journal of Zoology, 30, 421-441.

Macdonald, D.W., King, C.M. \& Strachan, R. (2007) Introduced species and the line between biodiversity conservation and naturalistic eugenics. In Key Topics in Conservation Biology (eds D.W. Macdonald \& K. Service), pp. 186-205. Blackwell Publishing, Oxford, UK.

McLeod, L.J., Saunders, G.R., McLeod, S.R., Dawson, M. \& VAN DE VEN, R. (2010) The potential for participatory landscape management to reduce the impact of the red fox (Vulpes vulpes) on lamb production. Wildlife Research, 37, 695-701.

McLeod, L.J., Saunders, G.R. \& Miners, A. (2011) Can shooting be an effective management tool for foxes? Preliminary insights from a management programme. Ecological Management and Restoration, 12, 224-226.

NBN Gateway (2012) Grid map for Neovison vison (Schreber, 1777) [American Mink]. Http://data.nbn.org.uk/Taxa/NHMSYS 0020774297/Grid_Map [accessed 12 May 2012].

Nordström, M., Högmander, J., Laine, J., Nummelin, J., LAanetu, N. \& KorpimäKi, E. (2003) Effects of feral mink removal on seabirds, waders and passerines on small islands in the Baltic Sea. Biological Conservation, 109, 359-368.

Nordström, M. \& KorPIMÄKI, E. (2004) Effects of island isolation and feral mink removal on bird communities on small islands in the Baltic Sea. Journal of Animal Ecology, 73, 424-433.

Peris, S.J., Sanguinetti, J. \& Pescador, M. (2009) Have Patagonian waterfowl been affected by the introduction of the American mink Mustela vison? Oryx, 43, 648-654.
Ratcliffe, N., Bell, M., Pelembe, T., Boyle, D., Benjamin, R., White, R. et al. (2010) The eradication of feral cats from Ascension Island and its subsequent recolonization by seabirds. Oryx, 44, 20-29.

Ratcliffe, N., Craik, C., Helyar, A., Roy, S. \& Scott, M. (2008) Modelling the benefits of American Mink Mustela vison management options for terns in west Scotland. Ibis, 150, 114-121.

Reynolds, J.C., Short, M.J. \& Leigh, R.J. (2004) Development of population control strategies for mink Mustela vison, using floating rafts as monitors and trap sites. Biological Conservation, $120,533-543$.

Scottish Natural Heritage (2012) Hebridean Mink Project: Introduction-Phase I and Phase II. Http://www.snh.gov.uk/landand-sea/managing-wildlife/hebridean-mink-project/introduction-phase-1-and-phase-2/ [accessed 12 May 2012].

Selge, S., Fischer, A. \& van der Wal, R. (2011) Public and professional views on invasive non-native species-A qualitative social scientific investigation. Biological Conservation, 144, 3089-3097.

Simberloff, D. (2001) Eradication of island invasives: practical actions and results achieved. Trends in Ecology and Evolution, $16,273-274$.

Smith, R.K., Pullin, A.S., Stewart, G.B. \& Sutherland, W.J. (2010) Effectiveness of predator removal for enhancing bird populations. Conservation Biology, 24, 820-829.

Tidwell, L.S. \& BRUnson, M.W. (2008) Volunteering to manage rangeland weeds: results of a citizen survey in the southwestern United States. Rangelands, 30, 19-24.

Universities Federation for Animal Welfare (2012) UFAW Wild Animal Welfare Award. Http://www.ufaw.org.uk/wawa.php [accessed 17 May 2012].

Williams, F., Eschen, A., Harris, A., Djeddour, D., Pratt, C., Shaw, R.S. et al. (2010) The Economic Cost of Invasive Non-Native Species on Great Britain. CABI, Wallingford, UK.

Wilson, M.J.L. (2008) Loch Sunart Mink Control Scheme. Mink Trapping Supervisors Final Report (unpublished). Scottish Natural Heritage, Fort William, UK.

\section{Biographical sketches}

Elaine Fraser is interested in applying scientific research to conservation practice, in particular for invasive species management. Her main area of research is currently the management and control of American mink in Scotland. David Macdonald specializes in researching practical questions in wildlife conservation. He has worked on invasive American mink for 15 years. ROS BRYCE'S interests include upland ecology and the use of participatory and interdisciplinary approaches to understand and improve decision-making related to conservation management practice and policy. XAVIER LAMBIN is a population ecologist with an interest in the use of participatory and adaptive management approaches for conservation. 